\title{
Fatigue failure of a welded automotive component
}

\author{
L.B.Godefroid ${ }^{\mathrm{a} *}$, G.L.Faria ${ }^{\mathrm{a}}$, L.C.Cândido ${ }^{\mathrm{a}}$, S.C.Araujo ${ }^{\mathrm{a}}$ \\ ${ }^{a}$ Federal University of Ouro Preto, REDEMAT,Campus Universitário do Morro do Cruzeiro s/n, Ouro Preto35400-000, Brazil
}

\begin{abstract}
Automotive components are commonly tested in fatigue before the final assembly of the vehicle, to ensure the accomplishment of technical specifications of the customer, and to avoid premature failure and accidents with autos. This work investigated the cause of failure of a control arm (component of the automobile movement system), made of high strength and low alloy steel, stamped and welded by robot procedure. The fatigue cracking of the component occurred during the application of standardized blocks of fatigue loading. All standard procedures of failure analysis were applied, with a careful assessment of the material characteristics and the cracked surface. It was concluded that fatigue cracks initiated near the weld bead, at the beginning of the welding procedure. An in-depth analysis of this region showed that there was presence of stress concentration, and the microstructure of the steel has been completely changed, due to an excessive amount of heat at the beginning of the welding. A recommendation to change the welding procedure was performed, ensuring the lifetime specified for the component in the fatigue test.
\end{abstract}

(C) 2014 Published by Elsevier Ltd. Open access under CC BY-NC-ND license.

Selection and peer-review under responsibility of the Norwegian University of Science and Technology (NTNU), Department

of Structural Engineering

Keywords: Automotive component; robot welding; fatigue cracking.

\section{Introduction}

Control arms are components that belong to the automobile suspension system. They are composed by transverse rods with three fixation points: two of them use elastic joints fixed to the car body or to the car front deck ("sub-

\footnotetext{
* Corresponding author. Tel.: 55.31.35591106; fax: 55.31.35591561.

E-mail address: leonardo@demet.em.ufop.br
} 
frame"); the third is fixed by a pivot "ball 7 joint" to the wheel hub. They are also fixed to the bumper and to the spring. According to technical literature, the control arms are usually manufactured with high strength low carbon steel (Gillespie 1992, Delaney 2002, Godefroid 2008), manufactured by stamping and welding procedures.

An adopted concept in automobile companies aiming to ensure the quality of their components, including the control arm, is the reliability concept, which is defined as the probability of the system execute its function during a specified time without fail (Kapur and Lamberson 1997, Majeske 2003).

An important and careful quality control test that is applied to automotive components is the fatigue test. In this test, the component is submitted to several loading blocks, and must resist without fail, for a specified number of cycles usually determined by the client. Figure 1(a) shows a control arm being tested in fatigue by a automobile industry. The application of fatigue loads induces a stress distribution, as shown in Figure 1(b). It is possible to see a crack that nucleates and grows in a region of high stress concentration. This work investigates the cause of undesirable appearance of this fatigue crack.

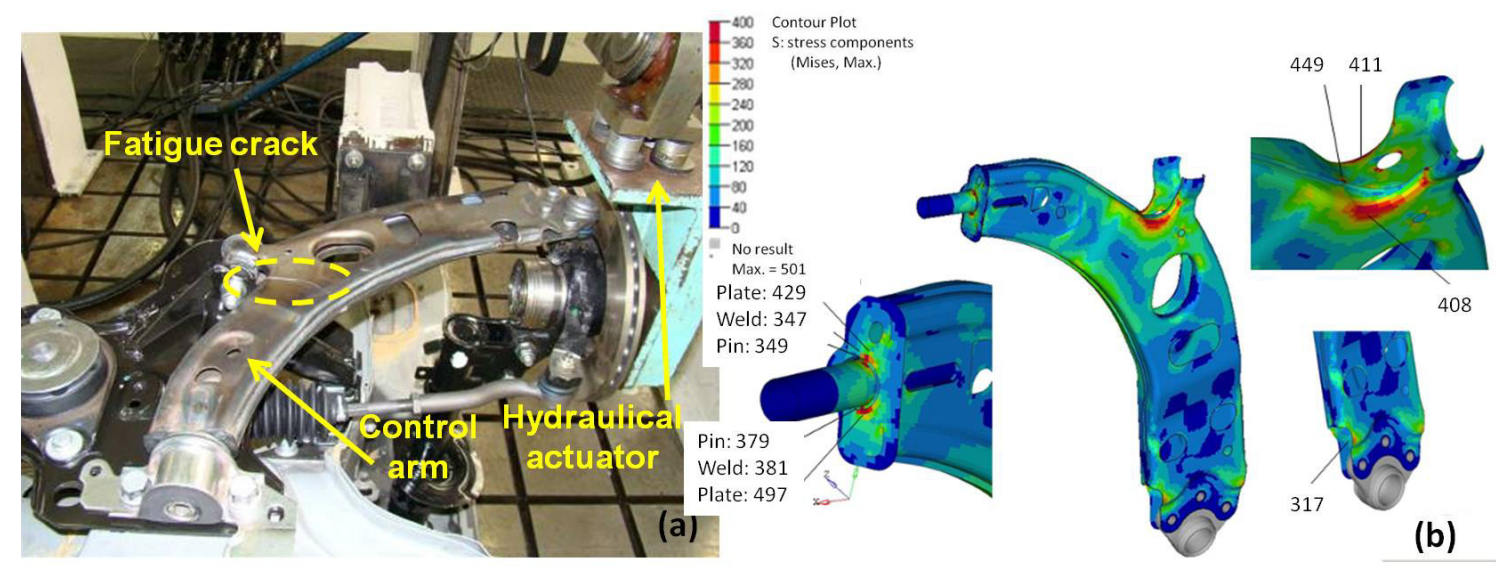

Fig. 1. (a) A control arm being tested by fatigue. (b) Stress analysis in the control arm.

\section{Materials And Methods}

Standard procedures for failure analysis were applied in this work. The analysis involved the following principal stages: investigation about material's fabrication and use history, sampling procedures including the preservation of the fractured surface, visual and microfractographic analysis, chemical analysis, metallographic analysis, and mechanical tests (tensile and microhardness tests).

\section{Results And Discussion}

\subsection{Visual Analysis}

Figure 2 (a) presents a control arm tested in fatigue. Figure 2(b) shows a detail near to the weld bead, where it is possible to see a crack. This crack started at a stress concentration area, exactly at the point where the welding procedure started. The big amount of deposited material in this region indicates that the welding process in this component started with a high heat input.

\subsection{Chemical Analysis}

Table 1 presents the chemical composition of the steels used in control arm manufacturing, after the stamping operation and after robot welding. The nominal values specified by NBR 6656 LNE 50 (Brazilian standard) for this kind of automotive component is also presented. Comparing the obtained results, it is possible to conclude that both 
parts are constituted by the same steel, and that the steel is in accordance with the standard. The content of microalloying elements $(\mathrm{V}+\mathrm{Ti}+\mathrm{Nb})$ should be a little higher, to ensure their benefits in mechanical properties (solid solution + grain size control + precipitation).

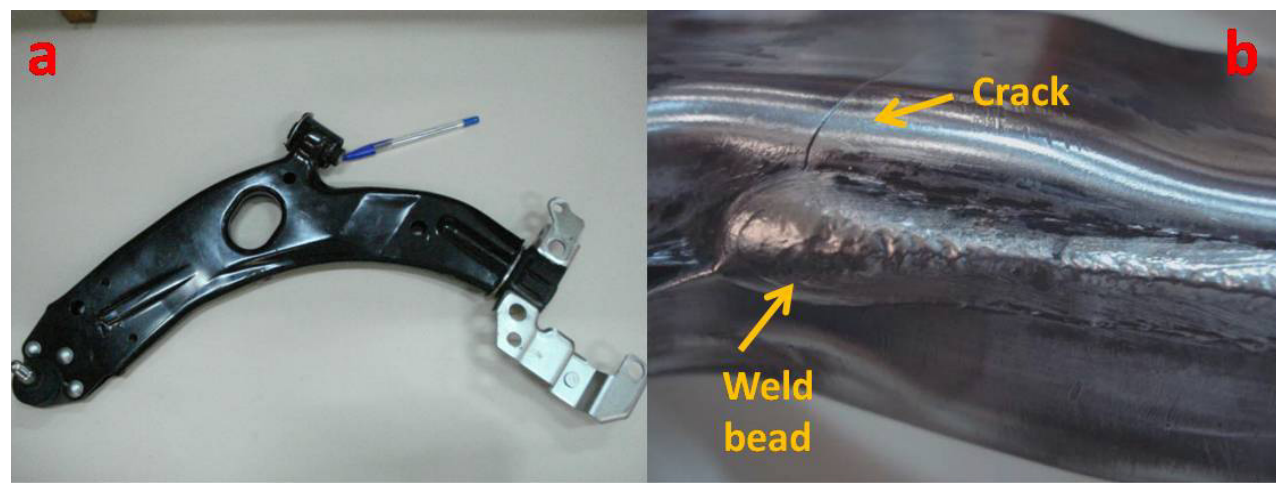

Fig. 2. (a) A control arm after a fatigue test. (b) Detail of the fatigue cracking at the weld bead.

Table 1: Comparison between chemical composition of stamped and welded sheets used in the control arm, as well as specified values presented by NBR 6656 LINE 50 (wt \%).

\begin{tabular}{cccccccccc}
\hline & $\mathbf{C}$ & $\mathbf{S i}$ & $\mathbf{S}$ & $\mathbf{P}$ & $\mathbf{M n}$ & $\mathbf{V}$ & $\mathbf{T i}$ & $\mathbf{N b}$ & $\mathbf{A l}$ \\
\hline Stamped & 0.11 & 0.05 & 0.007 & 0.022 & 1.32 & 0.002 & 0.03 & 0.04 & 0.04 \\
\hline Welded & 0.12 & 0.05 & 0.007 & 0.023 & 1.32 & 0.002 & 0.03 & 0.04 & 0.04 \\
\hline NBR & $0.12 \max$ & $0.35 \max$ & $0.015 \max$ & $0.030 \max$ & $1.50 \max$ & $0.12 \max$ & $0.20 \mathrm{max}$ & $0.12 \max$ & $0.020 \mathrm{~min}$ \\
\hline
\end{tabular}

\subsection{Metallographic Analysis}

Figure 3 illustrates the microstructure of the steel used both in stamped parts and in the welded control arm (optical microscopy-OM). It is a microstructure with fibering, consisting of elongated grains of ferrite and pearlite. This microstructure is typical of a high strength low alloy steel (HSLA). Fibering is derived from the forming process used in the manufacture of the material, and probably will confer anisotropy of mechanical properties to the material. The grain size of the phases present is small, showing the effect of microalloying elements in the material. As a result, it is expected that the material will have a relatively high mechanical strength.

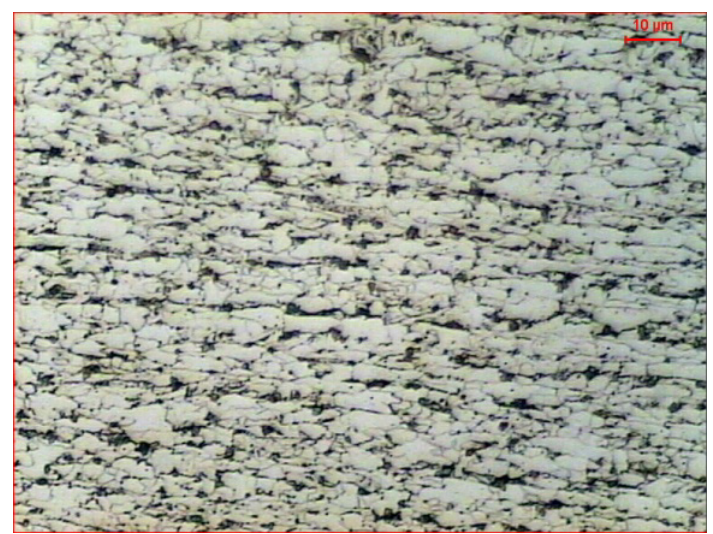

Fig. 3. Microstructure of the steel used in the control arm. (Nital 2\%, OM 1000X). 
Significant microstructural variation exists in the weld bead, being possible to distinguish the traditional microstructures of base metal (BM), heat affected zone (HAZ) and molten zone (MZ), as shown in Figure 4. The beneficial effects of microalloying elements will be minimized in this region.
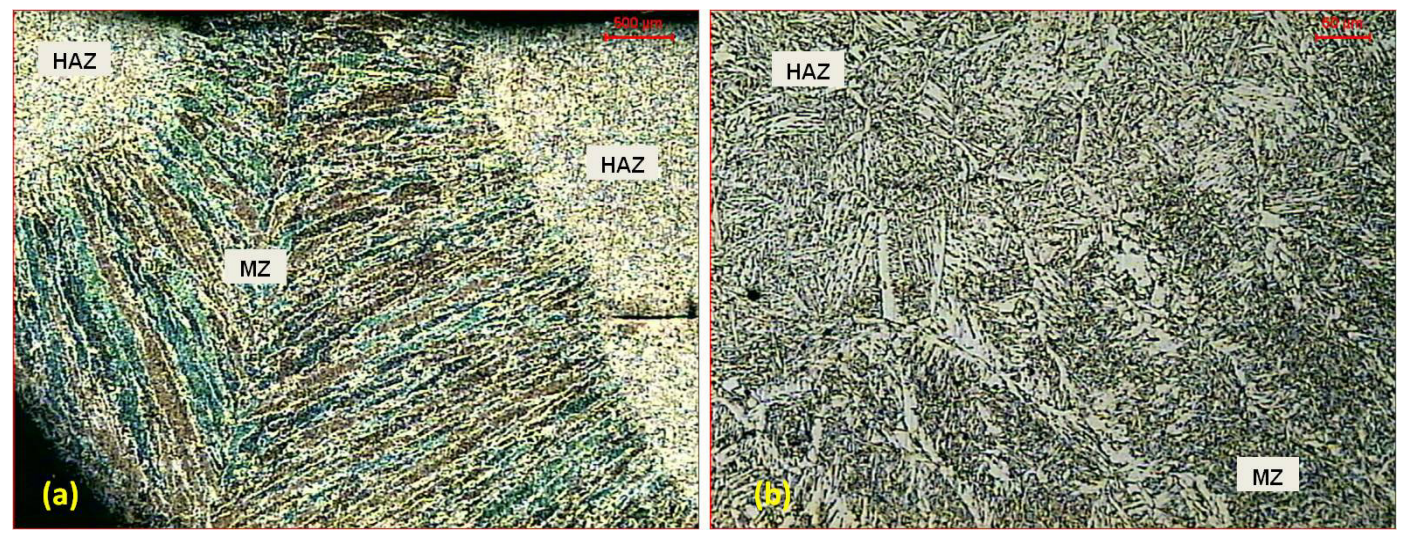

Fig. 4. Microstructure of the welded joint. (Nital 2\%, OM). (a) 25X; (b) 200X.

According to observation mentioned on visual analysis, in the region where the fatigue cracking under analysis starts (which corresponds to the beginning of the welding process) it's possible to see the application of a heat input greater than the rest of the welding procedure. Consequently, the microstructural variations in this region are more intense. This fact can be demonstrated in Figure 5, which corresponds to the region immediately below the fatigue cracking. This picture corresponds to a plane perpendicular to the fracture surface. The microstructure observed in this figure is close to the heat affected zone (HAZ).

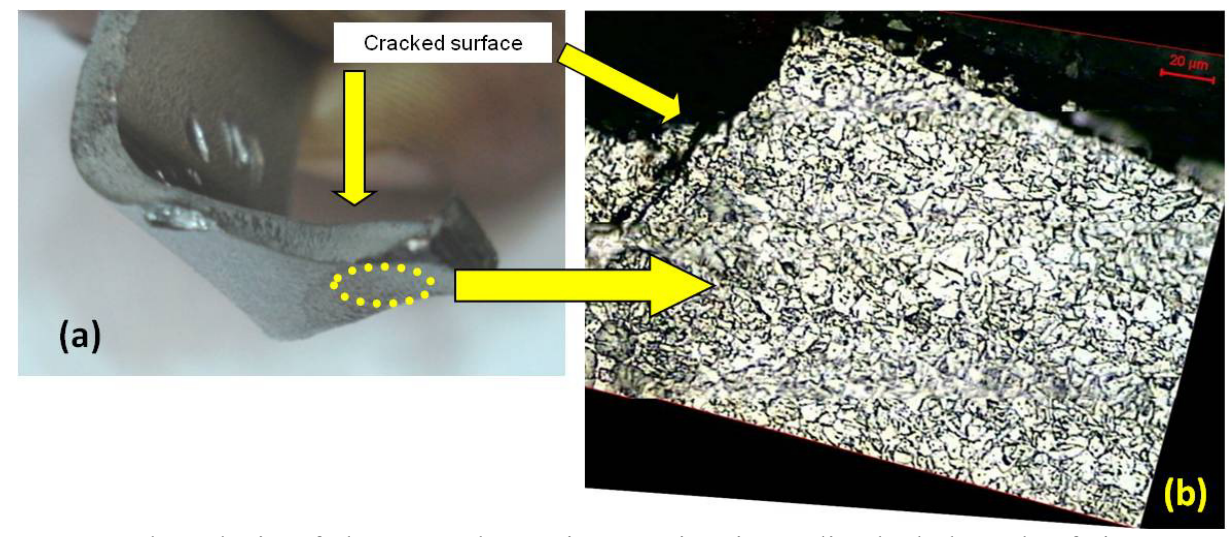

Fig. 5. Microstructural analysis of the control arm in a region immediately below the fatigue cracking. (a) the analyzed region; (b) corresponding microstructure. (Nital 2\%, OM, 500X).

\subsection{Mechanical Tests}

Table 2 presents the main mechanical properties obtained in tensile tests of three specimens sampled from the stamped and from the welded material. To promote the comparison between the expected and obtained results, the specified values by NBR 6656 LINE 50 are also presented. 
Table 2: Comparison between the main mechanical properties obtained by tensile tests.

\begin{tabular}{ccccc}
\hline & $\begin{array}{c}\text { Strain } \\
\mathbf{( \% )}\end{array}$ & $\begin{array}{c}\text { Area Reduction } \\
(\mathbf{\%})\end{array}$ & $\begin{array}{c}\boldsymbol{\sigma}_{\mathbf{y s}} \\
(\mathbf{M P a})\end{array}$ & $\begin{array}{c}\boldsymbol{\sigma}_{\text {ts }} \\
(\mathbf{M P a})\end{array}$ \\
\hline Stamped & $18 \pm 5$ & $60 \pm 5$ & $545 \pm 10$ & $602 \pm 7$ \\
\hline Welded & $22 \pm 4$ & $59 \pm 2$ & $544 \pm 10$ & $605 \pm 6$ \\
\hline NBR & $18 \mathrm{~min}$ & - & $500-600$ & $500-700$ \\
\hline
\end{tabular}

As already noted by chemical analysis and metallographic analysis, the steel stamped corresponds to the steel employed in the control arm. It is possible to observe that the steel used in the manufacture of the control arm is in accordance with the specification. The values found for the yield and the tensile stress lead to the conclusion that this is a steel of high strength in comparison to materials used in the automotive industry. On the other hand, in the weld region, as there was significant microstructural heterogeneity, the values shown in Table 2 should vary in order to decrease the mechanical resistance of the material.

Figure 6 presents the results obtained with microhardness tests carried out in the control arm in the area of the weld bead. It's possible to see clearly the microhardness decreasing from the base metal (BM) to the molten zone (MZ). This variation is due to the change of microstructure on material, as already observed in metallographic analysis. The dispersion of hardness values in the base metal is relatively large, due to the different constituents of the microstructure (ferrite and pearlite). The molten zone has lower hardness than the base metal. This result is not often found in welded joints, but is related to the type of electrode used in welding and with the characteristics of the welding process. The heat affected zone (HAZ) presented the lowest microhardness. This result can be justified by the pearlite fragmentation and cementite spheroidization in this area due to the high heat input from the welding procedure. These results confirm the predictions of loss of mechanical properties in the weld bead, as commented in the previous items.

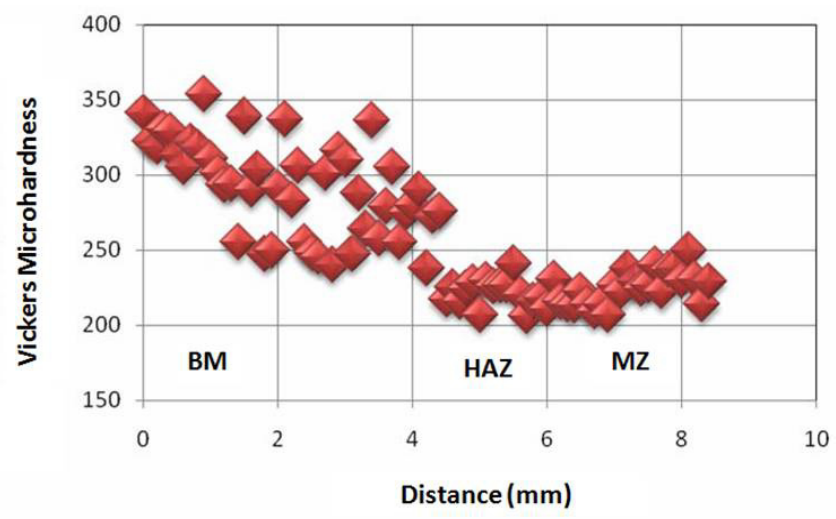

Fig. 6. Vickers microhardness profile at the welded joint.

\subsection{Fractographic Analysis}

Figure $7(a, b)$ presents a part of the control arm, where the crack appeared during the fatigue test. The numbering indicates regions that were subsequently analyzed in a scanning electron microscopy (SEM), as shown in Figure $8(\mathrm{a}-\mathrm{c})$. The mechanism of damage shows evidence of fatigue cracking, with crack initiation in the region of greater amount of heat in the weld bead (region 1), following of crack growth (region 2) until the stopping point of the fatigue test (region 3). At this point, the sample was deliberately broken, and the mechanism was changed to ductile fracture. 


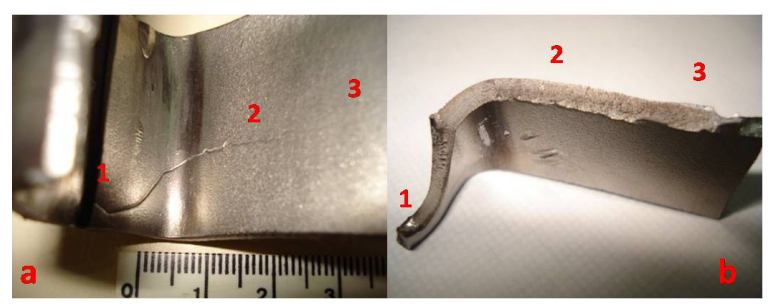

Fig. 7. Cracked part of the control arm, (a) before and (b) after delibarate tearing. Numbers 1, 2 and 3 indicate areas used for the microfractographic analysis in a SEM.
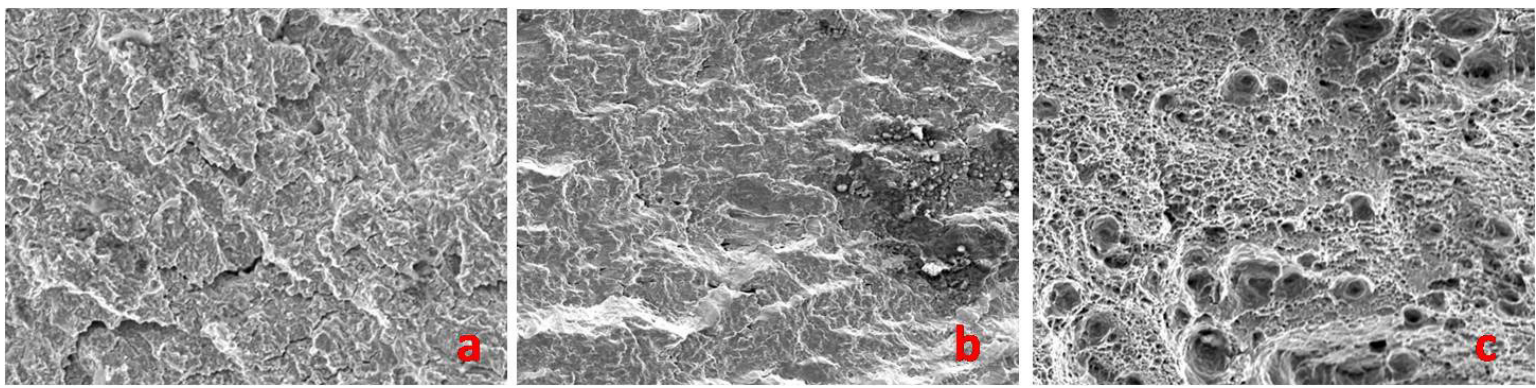

Fig. 8. Microfractography of (a) area 1;(b) area 2. (c) area 3. SEM 500X.

\section{Conclusions and recommendations}

The failure of the automobile control arm occurred during a standardized test of fatigue with crack initiation in a region of stress concentration, associated with the beginning of the welding procedure.

The stress analysis performed has detected the presence of stress concentration, particularly in the region of the fatigue cracking. The stress concentration is a function of the geometry of the control arm. As geometry changes probably should be out of the question, it's important to live with the problem, using a material resistant to this variable.

The studied steel has a chemical composition and tensile mechanical properties that are in accordance with the specification to this application. The microstructure is typical of a HSLA steel, consisting of ferrite and pearlite with fibering, and with relatively small grain size. On the other hand, it would be interesting to consider the replacement of the steel in question by another one within modern proposals of materials for automotive purposes, with higher levels of microalloying elements, to ensure the well-known beneficial effects of these elements in the increase of mechanical properties and weldability.

The beginning of the welding procedure occurs with high material deposition, indicating that it is made with relatively high heat input. The fatigue cracking initiated in this region. This high amount of heat produces a microstructural variation, leading to significant loss of material properties. It would be interesting to change the welding procedure, to greater homogenization and microstructural behavior.

\section{References}

Delaney, Michael. Double Wishbone vs. MacPherson Strut I:The Basics. USA: Team Integra, 2002. Disponible in: http://www.team-integra.net. Accessed on: 05 jul. 2006.

Gillespie, Thomas D. Fundamentals of Vehicle Dynamics. USA: SAE, 1992.

Kapur, K. C.; Lamberson, L. R. Reliability in Engineering Design. $1^{\text {st }}$ ed. New York: John Wiley \& Sons, 1977. Majeske, K.D. A Mixture Model for Automobile Warranty Data. Reliability Engineering and System Safety. V. 81, p. 71-77, 2003.

Godefroid, L.B. Tenacidade à fratura e resistência à fadiga de aços aplicados na indústria automobilística. $63^{\circ}$ Congresso Anual da ABM, Santos, SP, Brazil, 2008. 